\title{
Genu Varum
}

National Cancer Institute

\section{Source}

National Cancer Institute. Genu Varum. NCI Thesaurus. Code C84726.

A deformity of the legs characterized by medial angulation, resulting in a bow appearance. 